Neam N Al-Yousifany BDS, MSc (Lect)

\section{An Evaluation of Proximal Caries Managements among Practitioners in Mosul City.}

\author{
Department of Conservative Dentistry \\ College of Dentistry, University of Mosul
}

\begin{abstract}
Aims: To evaluate the diagnostic methods, preparation techniques and restorative materials used by dentists in Mosul City for the management of proximal carious lesions. Materials and Methods: A questionnaire sheet with numerous items were distributed randomly among 150 dentists (specialists and non-specialists) working in Mosul City. The sheets were collected and the data were analyzed. Results: The results revealed that there are several differences in performing specific steps of proximal caries diagnosis and the treatment among the dentists involved. Conclusions: The conclusions of this study indicated that the variations among dental practitioners in managing proximal caries refer to the role of the continuing dental education. Dentists are in need to be in contact through meetings, lectures and training courses with the recent and up-to-date advancement in dentistry.

Key words: Proximal caries, dental decision.
\end{abstract}

Al-Yousifany NN. An Evaluation of Proximal Caries Managements among Practitioners in Mosul City. Al-Rafidain Dent J. 2007; 7(SpIss): 113S-118S

Received: $28 / 1 / 2007 \quad$ Sent to Referees: $17 / 2 / 2007$

Accepted for Publication: 24/4/2007

\section{INTRODUCTION}

Caries is nowadays understood to be a dynamic process episodes of demineralization and remineralization occur over various periods of time. Operative intervention indicated only when there is macroscopic break down of teeth structure; i.e., when a cavity has formed ${ }^{(1)}$. The majority of dental practitioners need to spend much of their time deciding whether lesions of caries are present or not and to make a judgment on how to treat such lesions $^{(2)}$.

Diagnosis of proximal lesions are difficult, because of the restricted access to the examination. Clinicians need several methods of diagnosis to investigate these surfaces ${ }^{(3)}$.

Cavity preparation for such caries has been based on G.V. Black's principles which require an occlusal involvement. The current equipments and restorative materials permit more conservative geom.etric forms, also the reduction in bur dimension has allowed a minimal removal of tooth structure ${ }^{(1)}$.

Materials used for restoration of caries lesion include amalgam, composite resin, glass ionomer, porcelain and gold. Composite resin match the color of pa- tient's natural teeth and thus used more frequently when esthetic care was concerned $^{(4)}$.

The variation in decision making about management of caries have been demonstrated among dentists in several countries. Such studies need to assess the restorative treatment philosophies ${ }^{(4-7)}$.

The aims of this study were mapping the diagnostic methods, preparation techniques and restorative materials that dentists in Mosul City are used, for management of proximal caries lesions.

\section{MATERIALS AND METHODS}

For the present study, a questionnaire sheet that concerned with different methods of proximal caries diagnosis and management were prepared and delivered among 150 dentists. They were selected randomly from different centers in Mosul City (Health Centers and Dentistry College). The dentists involved in the study were both specialists and non specialists.

The questionnaire sheet did not contain the name of the dentist who filled it. The sheets were collected from the respondents and subjected to analysis, arrangement and tabulation. 


\section{RESULTS}

From the total number of dentists involved in the study, $48 \%$ of them male others are females. Regarding to the specialty, $68 \%$ were specialists and $32 \%$ were not. The average number of teeth treated per week ranged from 5 teeth to 25 teeth. The largest number of dentists treated 10 teeth/ week, Table (1). Most of dentists who treated 20 teeth and over per week were specialists in Conservative Dentistry.

When the respondents were asked about using radiograph as a method of caries diagnosis in the proximal surfaces, $96 \%$ of the respondent out of (144 dentist) replied that they used this technique for diagnosis, and $47 \%$ of them preferred bitewing radiograph, while 53\% preferred using bisecting angle technique, Table (2).

Visual and tactile examination were chosen by all respondents as another means usually depending on diagnosis.

Only 4\% (6 dentist) preferred Fiber Optic Trans-Illumination (FOTI) as a method of a proximal lesions diagnosis, that revealed with Table (3).

Carious lesion confined to the enamel had been restored by $24 \%$ of the dentists, while $40 \%$ waited until the lesion was progressed into dentin, $18 \%$ treated the carious lesion when radiolucency is present in $\mathrm{x}$-ray radiograph.

The remaining $8 \%$ treated lesion only when the cavitation occurred in the tooth.

The percentage of dentists treated the proximal lesion with restoration using a combination of dentine caries and radiolucency was $20 \%$, Table (4).

When the respondents were asked about the preferable proximal cavity design, the traditional $\mathrm{Cl}$ II cavity preparation was the design of choice by 114 dentists (76\%), 18 dentists (12\%) preferred box preparation although not all of them used adhesive for such design, 12 dentists $(8 \%)$ used tunnel preparation, and only 6 dentists $4 \%$ preferred the saucer design, Figure (1).

A variety of materials are available for restoring the prepared cavities, the most commonly used are amalgam and composite resin material. In this study, amalgam was preferred over a composite in the opinion of $144(96 \%)$ respondents, while only $6(4 \%)$ preferred composite and no one used glass Ionomer cement, as shown in Figure (2).

Table (1): Average number of carious teeth treated per week by the dentists.

\begin{tabular}{cc}
\hline Number of dentists & tooth/ week \\
\hline 24 & 5 \\
24 & 6 \\
6 & 7 \\
6 & 8 \\
42 & 10 \\
12 & 15 \\
30 & 20 \\
6 & 25 \\
\hline
\end{tabular}

Table (2): Radiographs used for diagnosis of proximal caries.

\begin{tabular}{cccc}
\hline \multicolumn{2}{c}{ Use of radiograph } & Type of radiograph & Percentage \\
\hline Yes & $96 \%$ & Bisecting angle technique & $53 \%$ \\
No & $4 \%$ & Bit-wing & $47 \%$ \\
\hline
\end{tabular}

Table (3): Percentage of diagnostic methods used by the dentists.

\begin{tabular}{cc}
\hline Diagnostic method & Percentage \\
\hline Visual and tactile & $100 \%$ \\
Radiograph & $96 \%$ \\
FOTI & $4 \%$ \\
Others & $0 \%$ \\
\hline
\end{tabular}


Table (4): Percentage of dentists according to the level of treatment caries.

\section{Level of caries}

Lesion on enamel

Dentin lesion

Radiographical caries

Dentin lesion + radioluceny

Cavitation
Percentage of dentists

$24 \%$

$40 \%$

$8 \%$

$20 \%$

$8 \%$

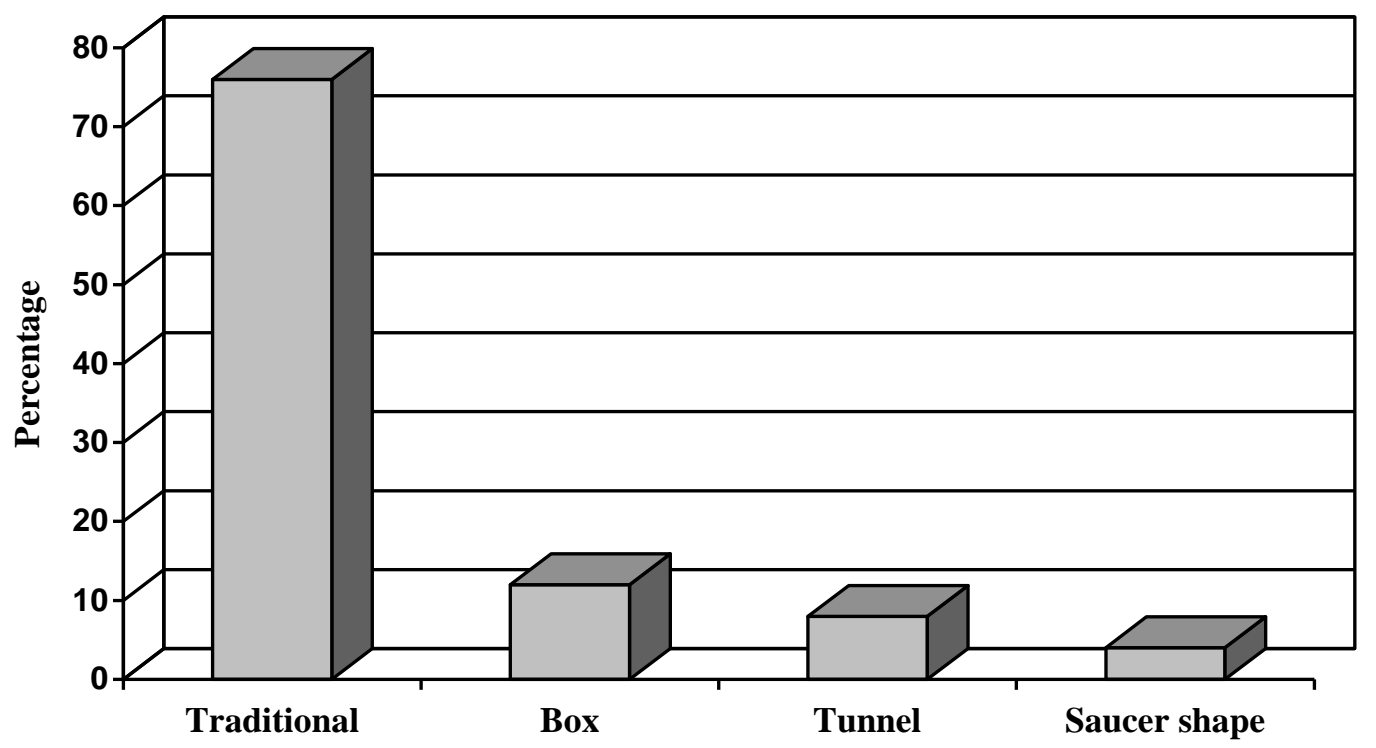

Figure (1): Percentage of four different cavity design.

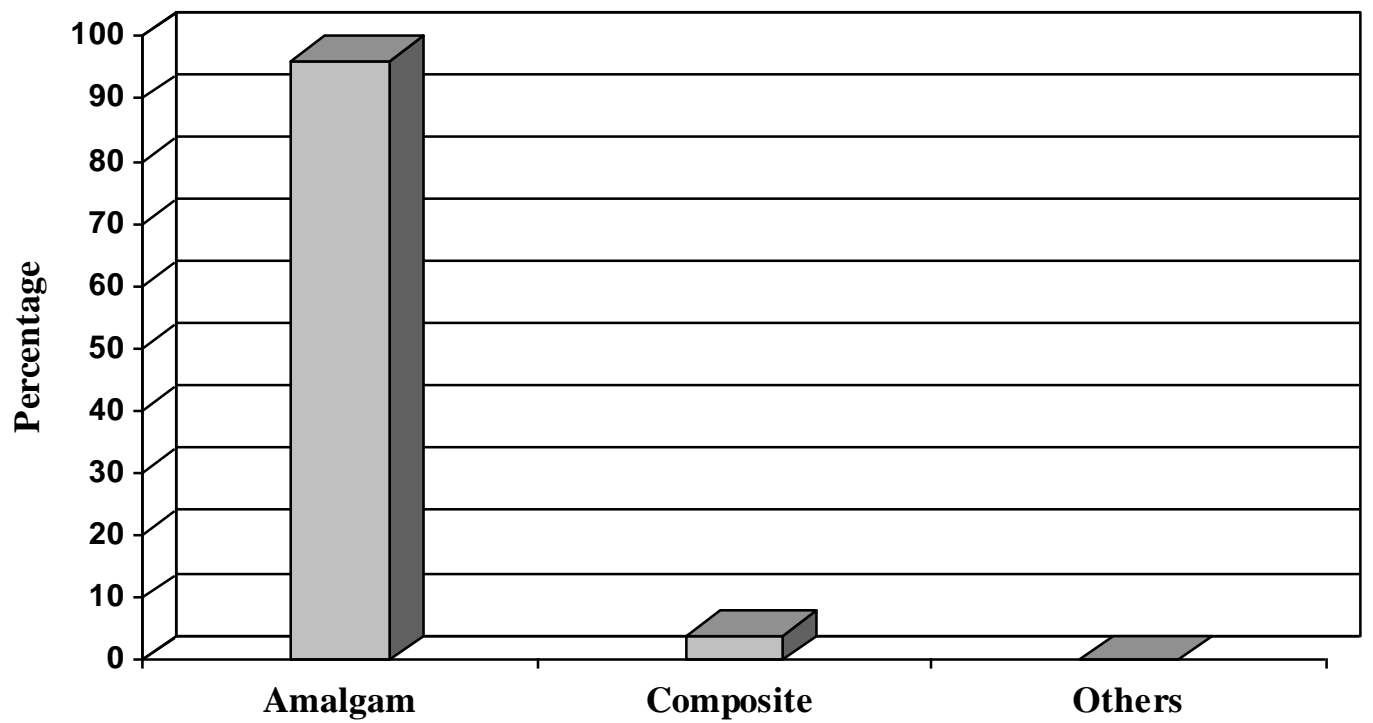

Figure (2): The types of restorative material used. 


\section{DISCUSSION}

A random sample of dentists in Mosul City were asked about the diagnosis and treatment of proximal caries, which type of cavity preparation and filling material they would prefer.

The result of this survey may be considered to represent a fair summary of current practices in Mosul City, and this may help in encouraging "Dental Facult-ies" to develop a consensus on issues related to diagnosis and management of dental caries.

Several studies revealed a variation in decision making about the restorative treatment that have been demonstrated among dentists in several countries ${ }^{(4-8)}$.

This study assessed the restorative treatment philosophies based on the representative sample of Mosul dentists.

The dentists need to modify their operative treatment practices in the light of modern philosophies. Black's cavity preparation principles have long guided dentists restorative strategies, but in recent years , better understanding of caries process has changed the operative treatment philosophies now. Preventive strategies involving fluoride and enhance the remineralization are preferred, operative treatments are however undesirable unless the carious lesion has reached an advanced stage of cavitation $^{(9)}$.

For individual treatment planning, caries in the proximal surfaces have traditionally been diagnosed by clinical examination combined with radiography ${ }^{(10)}$, and these methods are still employed frequently among dentists. For this reason, high percentage of respondents use radiographs for diagnosis of proximal lesions. The radiograph is considered to be the most common adjunct to the visual and tactile clinical examination.

Practically, clinical examination must precede the radiographic examination in an individual treatment planning and selective radiography should be performed in cases in which a clinical examination has lead to a suspected lesion ${ }^{(10)}$.

Other methods of diagnosis like Fiber Optic Trans-Illumination (FOTI) used by very low percentage of dentists, cannot be used as a method of choice for identification of proximal surface of permanent teeth. The low sensitivity value of this methods may be due to that, with FOTI examination; we considered a shadow seen in the dentine as a sign of cavitation, and the majority of shadows reported were assessed to be confined to enamel only ${ }^{(10)}$.

The study showed a considerable variability in the responses with regard to the rate of proximal lesion progress from outer enamel to dentine, less than half of respondents decided to restore the proximal lesions, when caries reach to dentine (the higher percentage were in among the specialists). The treatment of lesion when it is confined to enamel was the answer of $1 / 4$ of respondents.

Similar survey on Swedish, indicated that $1 / 3$ of dentists did not treat the lesion in enamel ${ }^{(6)}$. In Norway, $81 \%$ of dentists waited until the lesions reached dentine ${ }^{(7)}$.

Eighty eight percent of French practitioners would have prepared the proximal lesion when reached amelodentinal junc$\operatorname{tion}^{(4)}$.

While, in Scotland, many dentists would fill an proximal lesion, when radiolucency was confined to enamel ${ }^{(11)}$.

A survey on the beliefs and attitudes of French University teachers in operative dentistry illustrated a wide disparity among them, particularly concerning the restorative treatment threshold of proximal surfaces, only $39.1 \%$ of respondents would have waited until the lesion was in dentine, carious lesions confined to enamel would have been operatively restored by $21.9 \%$ of the respondents ${ }^{(12)}$.

An over estimation of the speed at which dental caries progress through the enamel, and lack of good knowledge about the opportunities for the remineralization of enamel lesions with fluorides are largely affected by the tendency to restore carious lesion. For example, dentists who knew about the slow progression of lesion delayed the surgical treatment of it until the caries penetrates the dentin.

The percentage of proximal lesions that progressed from enamel into dentine was calculated by Brabner et al., for individual subject to a low fluoride expos-ure, between 50 and 60 percent of enamel lesion progress into dentin over a period of three to four years ${ }^{(13)}$. 
Mejare et al. determined that $75 \%$ of lesions in enamel did not progress into the dentin in group of adolescents over a period of 4.8 years ${ }^{(14)}$.

It can be hypothesized that these differences among the dentist opinions illustrated their understanding of the cari-ous process and his/ her level of confiden-ce about the remineralization.

In this study, high percentage of respondents (76\%) used traditional Cl II cavity preparation, this finding suggested that many dentists have not modified their operative treatment practices in the light of modern philosophies. This may related to the high cost of newly introduced materials and their equipments that dentists need it to improve and develop their work.

Gorucu et al. suggested that it may be unnecessary to extend $\mathrm{Cl}$ II preparations across the occlusal non carious grooves, sealing the non carious fissures more conservative than included in the preparations ${ }^{(3)}$.

The practitioner in Mosul City mainly used amalgam restoration for traditional $\mathrm{Cl}$ II preparation, while the majority of French dentists preferred composite materials $^{(4)}$. In Norway, fifth of the dentists choose amalgam and others used different types of color restorative materials ${ }^{(7)}$.

In California, non amalgam materials are significantly popular among dentis$\mathrm{ts}^{(15)}$. Clinical evaluation of posterior composite material concluded that with the improvement in materials, careful case selection and application of restorative technique, posterior composite can placed under appropriate conditions and monitored routinely can be expected to last 10 years or longer ${ }^{(16)}$.

The high cost and demanded operative technique remained the main criticisms with amalgam alternatives.

Addition of an adhesive system improved fracture value for different types of preparation $^{(3)}$. The effectiveness of adhesive agents used in proximal lesions, studied by numbers of investigators, the results demonstrated that the preparations with the adhesive systems indicated a higher resistance to dislodging load than the preparations without adhesive ${ }^{(3,17)}$.

The results of this study support the need for continuing education programs in management of dental caries, because the goal of conservative management is to preserve as much of the existing tooth structure as possible.

\section{CONCLUSIONS}

Large numbers of dentists (mainly the specialist) updating their knowledge and beliefs about management of proximal dental caries, while others do not diagnose or treat such lesions correctly.

These variations have important implication for continuing dental education. Dentist need to be in contact with the most recent advancement in dentistry fields. This could lead to the consistent and modern management of the carious proc-ess, which could be advantageous to the patients.

\section{REFERENCES}

1. Tan PIB, Evans RW, Morgan MV. Caries, bitwings and treatment decisions. Australian Dental J. 2002; 47(2): 138-141.

2. Anders Thylstrup FJT, Burker NHF, Wilson HF, Wilson FJ, Ma AM, When caries is caries and what should we do about it. Quintessence Int. 1998; $29: 9-12$

3. Gorucu J, Tiritoglu M and Ozgunaltay G. Effects of preparation designs and adhesive systems on retention of $\mathrm{Cl}$ II amalgam restoration J Prosthet Dent. 1997; 78: 250-254.

4. Domejean - orliaguet $S$, Tubert - Jeannin $\mathrm{S}$, Riordan PJ, Espelid I and Tveit AB. French dentist's restorative treatment decisions. Oral Health Prev Dent. 2004; 2(2): 125-131.

5. Espelid I, Tveit AB, Mejare I, Sundberg $\mathrm{H}$, Hallonsten AL. Restorative treatment decisions on occlusal caries in Scandinavia. Acta Odontol Scand. 2001; 59: 21-7.

6. Sundberg H, Mejar I, Espelid I, Tveit AB. Swedish dentists' decisions on preparation techniques and restorative materials. Acta Odontol Scand. 2000; 58: 135-141.

7. Tveit AB, Espelid I, Skodje F. Restorative treatment decisions on approximal caries in Norway. Int Dent J 1999; 49: 165-172.

8. Iewis DW, Main PA, Ontario dentists' knowledge and beliefs about selected aspects of diagnosis, prevention and restorative dentistry. J Can Dent Assoc. 1996; 62(4): 337-344. 
9. Mount GJ, Ngo H. Minimal intervention a new concept for operative dentistry. Quintessence Int. 2000; 31: 527-533.

10. Al-Yosifani NN, Al-Shaekh Ali MGH. Reliability of different methods for diagnosis of approximal carious lesion. $\mathrm{Al}-$ Rafidain Dent. J. 2002; 2: Special Issue 341-348.

11. Nuttall, NM, Pitts NB, Restorative treatment thresholds reported to be used by dentists' in Scotland. Br Dent J. 1990; 169(5): 119-126.

12. Tubert-Jeannin S., Domejean-Orliaguel S, Riordan PJ, Tveit AB. Restorative treatment strategies reported by French University teachers. J Dent Educ. 2004; 68(10): 1096-1103.

13. Brabner D, Downer MC, Molers DR, Naylor MN. Initial caries attack and average progression rates in 12-years-old Isle of weight children. Community Dent Health. 1995; 12: 190-193.

14. Merjare I, Kallest IC, Stenlund H, Incidence and progression of proximal caries from 11 to 22 years of age in Sweden: A prospective radiographic study. Caries Res. 1999; 3: 93-100.

15. Pair RL, Udin RD, Tanbonliong T. Material used to restore CL II lesions in primary molars: A survey of California Pediatric Dentists. Pediat Dent. 2005; 26(6): 501-507.

16. Turkun LS, Aktener BO. Twenty-four month clinical evaluation of different posterior composite resin materials. $J A m$ Dent Assoc. 2001; Feb 132(2): 196-203.

Staninec M. Retention of amalgam restorations. Undercuts versus bonding Quintessence Int. 1989; 20: 347-351. 